\title{
OPEN Functional expression of the eukaryotic proton pump rhodopsin OmR2 in Escherichia coli and its photochemical characterization
}

\begin{abstract}
Masuzu Kikuchi ${ }^{1,6}$, Keiichi Kojima ${ }^{1,2,6}$, Shin Nakao ${ }^{1}$, Susumu Yoshizawa ${ }^{3}$, Shiho Kawanishi ${ }^{2}$, Atsushi Shibukawa², Takashi Kikukawa ${ }^{4,5}$ \& Yuki Sudo ${ }^{1,2}$

Microbial rhodopsins are photoswitchable seven-transmembrane proteins that are widely distributed in three domains of life, archaea, bacteria and eukarya. Rhodopsins allow the transport of protons outwardly across the membrane and are indispensable for light-energy conversion in microorganisms. Archaeal and bacterial proton pump rhodopsins have been characterized using an Escherichia coli expression system because that enables the rapid production of large amounts of recombinant proteins, whereas no success has been reported for eukaryotic rhodopsins. Here, we report a phylogenetically distinct eukaryotic rhodopsin from the dinoflagellate Oxyrrhis marina (O. marina rhodopsin-2, OmR2) that can be expressed in E. coli cells. E. coli cells harboring the OmR2 gene showed an outward proton-pumping activity, indicating its functional expression. Spectroscopic characterization of the purified OmR2 protein revealed several features as follows: (1) an absorption maximum at $533 \mathrm{~nm}$ with all-trans retinal chromophore, (2) the possession of the deprotonated counterion $\left(\mathrm{p} K_{\mathrm{a}}=3.0\right)$ of the protonated Schiff base and (3) a rapid photocycle through several distinct photointermediates. Those features are similar to those of known eukaryotic proton pump rhodopsins. Our successful characterization of OmR2 expressed in $E$. coli cells could build a basis for understanding and utilizing eukaryotic rhodopsins.
\end{abstract}

To capture sunlight, organisms use a variety of photoreceptive proteins that are responsible for light-energy conversion and light-signal transduction in nature. Photoreceptive membrane proteins called microbial rhodopsins form large phylogenetic clusters in three domains of life, archaea, bacteria and eukarya ${ }^{1,2}$. Microbial rhodopsins consist of seven-transmembrane $\alpha$-helices covalently linked to the chromophore all-trans retinal, a derivative of vitamin- $\mathrm{A}^{2,3}$. The chromophore retinal covalently binds to a conserved Lys residue located in the 7 th helix of the rhodopsin apoprotein through a protonated Schiff base linkage ${ }^{3}$. After photoisomerization of the retinal from an all-trans to a 13-cis configuration, microbial rhodopsins undergo a series of cyclic reactions called a photocycle in which several spectrally distinct photointermediates are sequentially formed and the initial state is recovered along with the conformational changes ${ }^{3}$. During each photocycle, rhodopsins exhibit their biological functions such as ion transport and photosensing ${ }^{1-3}$. For instance, outward proton pumps produce the molecular currency adenosine triphosphate (ATP) through the formation of a proton gradient across the cell membrane like photosynthesis, indicating their physiological significance in microorganisms ${ }^{4}$.

Archaeal and bacterial rhodopsins have been the basis for research of microbial rhodopsins. Historically, bacteriorhodopsin (BR) was first rhodopsin discovered from the halophilic archaea Halobacterium salinarum as an outward proton pump in $1971^{5}$. After that, halorhodopsin and sensory rhodopsin I and II were identified from the halophilic archaea as an inward chloride pump and a phototaxis sensor, respectively ${ }^{1}$. Many other archaeal

\footnotetext{
${ }^{1}$ Division of Pharmaceutical Sciences, Okayama University, Okayama 700-8530, Japan. ${ }^{2}$ Graduate School of Medicine, Dentistry and Pharmaceutical Sciences, Okayama University, Okayama 700-8530, Japan. ${ }^{3}$ Atmosphere and Ocean Research Institute, The University of Tokyo, Chiba 277-8564, Japan. ${ }^{4}$ Faculty of Advanced Life Science, Hokkaido University, Sapporo 060-0810, Japan. ${ }^{5}$ Global Station for Soft Matter, GI-CoRE, Hokkaido University, Sapporo 001-0021, Japan. ${ }^{6}$ These authors contributed equally: Masuzu Kikuchi and Keiichi Kojima. ${ }^{\square}$ email: sudo@ okayama-u.ac.jp
} 
(A)

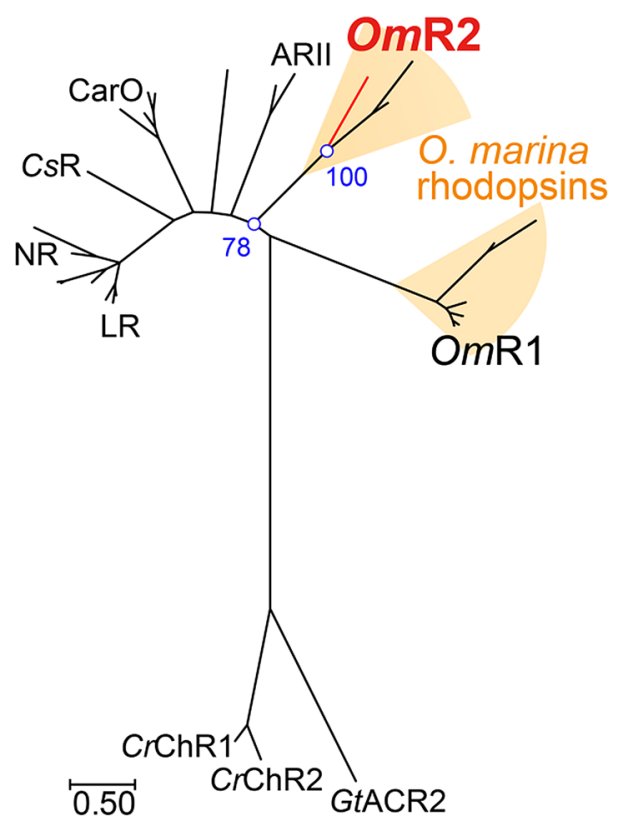

(B)

\begin{tabular}{|c|c|c|c|c|c|c|c|c|}
\hline OmR2 N & 85 & 8 & 92 & 99 & 191 & 201 & 209 & 213 \\
\hline $\mathrm{RN}$ & 82 & 85 & 89 & 96 & 194 & 204 & 212 & 216 \\
\hline $\mathrm{OmF}$ & R & & $T$ & D & $\mathrm{E}$ & \ulcorner & $D$ & $\mathrm{~K}$ \\
\hline OmR1 & $\mathrm{R}$ & D & $\mathrm{T}$ & $E$ & G & $E$ & D & K \\
\hline LR & $\mathrm{R}$ & $D$ & $\mathrm{~T}$ & $\mathrm{D}$ & D & $E$ & D & K \\
\hline ARII & $\pi$ & . & $\mathrm{T}$ & D & $S$ & $E$ & D & K \\
\hline$B R$ & $\mathrm{R}$ & D & $\mathrm{T}$ & $\mathrm{D}$ & $E$ & E & D & K \\
\hline AR3 & $\mathrm{R}$ & D & $\mathrm{T}$ & D & $E$ & $E$ & D & K \\
\hline $\mathrm{PF}$ & $\mathrm{R}$ & D & $\mathrm{T}$ & E & 1 & L & D & $\mathrm{K}$ \\
\hline TR & $R_{2}$ & D & $T$ & $E$ & W & I & D & K \\
\hline DY17 & $\mathrm{R}$ & ח & $T$ & E & G & $E$ & D & K \\
\hline משומה & $\mathrm{R}$ & 5 & $T$ & L & $G$ & $E$ & D & $\mathrm{K}$ \\
\hline ABV22427 & $\mathrm{R}$ & $\mathrm{D}$ & $T$ & $E$ & $G$ & $E$ & D & K \\
\hline$A D V \angle 2$ & $\mathrm{R}$ & U & $\mathrm{T}$ & $E$ & G & $E$ & L & $n$ \\
\hline $\mathrm{ABV} 2$ & $\mathrm{R}$ & $\mathrm{D}$ & $\mathrm{T}$ & $E$ & $G$ & $E$ & D & $\mathrm{K}$ \\
\hline AIN36 & $\mathrm{R}$ & $\mathrm{S}$ & $\mathrm{T}$ & $\mathrm{D}$ & V & $E$ & D & $\mathrm{K}$ \\
\hline AIIVOOS & $\mathrm{R}$ & $c$ & 1 & $D$ & V & $E$ & D & $\mathrm{K}$ \\
\hline AIN36549 & $\mathrm{R}$ & $S$ & $\mathrm{~T}$ & D & C & $\mathrm{E}$ & D & $\mathrm{K}$ \\
\hline
\end{tabular}

Figure 1. Characteristics of the eukaryotic rhodopsin OmR2. (A) Phylogenetic tree of microbial rhodopsins from eukaryotes (see "Methods" for detail). The scale bar indicates the number of substitutions per site. The numbers (i.e., 78 and 100) represent the bootstrap probabilities. (B) List of representative amino acid residues responsible for the function in $O m \mathrm{R} 2$ and the well-characterized outward proton pump rhodopsins, $O m \mathrm{R} 1$, LR, ARII, BR, AR3, PR, TR and O. marina rhodopsins (Genbank accession number: ADY17806, ADY17809, ABV22427, ABV22430, ABV22432, AIN36547, AIN36548, AIN36549). Abbreviations of the rhodopsins are as follows: Acetabularia rhodopsin II, ARII; archaerhodopsin-3, AR3; bacteriorhodopsin, BR; Chlamydomonas reinhardtii channelrhodopsin-1, CrChR1; Chlamydomonas reinhardtii channelrhodopsin-2, CrChR2; Coccomyxa subellipsoidea rhodopsin, CsR; Fusarium fujikuroi rhodopsin, CarO; Guillardia theta anion channelrhodopsin-2, GtACR2; Leptosphaeria maculans rhodopsin, LR; Neurospora crassa rhodopsin, NR; Oxyrrhis marina rhodopsin-1, OmR1; Oxyrrhis marina rhodopsin-2, OmR2; proteorhodopsin, PR; thermophilic rhodopsin, TR.

rhodopsins have also been extensively characterized photochemically and their ion transport and signal transduction mechanisms have been established at the atomic level with a high temporal resolution ${ }^{3,6}$. In 2000 , a bacterial outward proton pump rhodopsin, proteorhodopsin (PR), was identified from the marine $\gamma$-Proteobacteria, which opened a new era of genomic exploration of unknown microbial rhodopsins ${ }^{7}$. Since then, numerous bacterial rhodopsins, such as a thermally stable outward proton pump rhodopsin, thermophilic rhodopsin (TR), were identified from the extremely thermophilic bacterium Thermus thermophilus. An outward sodium pump rhodopsin, Krokinobacter rhodopsin 2 (KR2) from Krokinobacter eikastus, and a transcriptional regulator, Anabaena sensory rhodopsin (ASR), were unveiled by genomic analysis and have been extensively characterized as have archaeal rhodopsins ${ }^{7-12}$. To photochemically characterize rhodopsins in detail, large amounts of proteins are required. For rhodopsins from $H$. salinarum, abundant proteins can be obtained from the native and mutant strains of $H$. salinarum, which has accelerated their research. However, it has been difficult in general to obtain native proteins of many microbial rhodopsins from native organisms due to their low expression levels and the difficulty of cultivating cells that express them. In 1997, the functional expression of Natronomonas pharaonis phoborhodopsin ( $p \mathrm{pR}$ ) in Escherichia coli was achieved by Shimono et al. ${ }^{13}$, by which the acquisition of large amounts of proteins and the efficient production of many mutants can be performed efficiently. Since then, the E. coli expression system has been widely and successfully used for several types of microbial rhodopsins including the rhodopsins mentioned above ${ }^{9,14-16}, E$. coli-based expression system is the foundation for the molecular analysis of microbial rhodopsins.

Recently, advances in genomic analysis have revealed the presence of numerous microbial rhodopsins in eukaryotes (Fig. 1A). Neurospora crassa rhodopsin (NR) was identified from the filamentous fungus, Neurospora crassa, in 1999 although its molecular function was unclear ${ }^{17}$. After that, eukaryotic proton pump rhodopsins such as Leptosphaeria rhodopsin (LR) from Leptosphaeria maculans, Acetabularia rhodopsin I and II (ARI and ARII) from Acetabularia acetabulum, Oxyrrhis marina rhodopsin-1 (OR1 or OmR1) from the dinoflagellate, cation channel rhodopsins such as channelrhodopsin-1 and -2 from the alga Chlamydomonas reinhardtii ( $\mathrm{CrChR} 1$ and $\mathrm{CrChR2}$ ) and anion channelrhodopsins such as anion channelrhodopsin-1 and -2 from the alga Guillardia theta (GtACR1 and GtACR2), have also been identified and characterized ${ }^{18-20}$. In addition, eukaryotic ion transporting rhodopsins have attracted attention as a molecular tool for optogenetics ${ }^{21}$. While cation 
channelrhodopsins are used to induce neural activation, outward proton pump rhodopsins and anion channelrhodopsins are used to induce neural silencing ${ }^{21,22}$. Therefore, the molecular characterization of eukaryotic ion transporting rhodopsins should provide useful information for their modification and development as new optogenetics tools.

Although eukaryotic rhodopsins can be characterized by heterologous expression systems using yeast cells, Xenopus oocytes, mammalian cells, insect cells and cell-free systems ${ }^{23-25}$, it is generally difficult to achieve their functional expression in E. coli cells. Nonetheless, we previously succeeded in expressing $C r C h R 1$ in E. coli cells by truncating the $\mathrm{N}$ - and $\mathrm{C}$-termini of the proteins, although the truncated mutants showed constitutive activities that are different from the wild-type proteins ${ }^{26}$. We also succeeded in the functional expression and mutational analysis of GtACR2 in E. coli cells, which could provide a characteristic mutant for new optogenetics tools ${ }^{27-29}$. However, we were not able to purify the photoactive protein of GtACR2 from E. coli cells probably due to its denaturation during the solubilization step in detergent micelles. One research group fused the Mistic domain, a membrane-associated protein from Bacillus subtilis, into the $\mathrm{N}$ - and C-termini of ARI and CrChR1, to allow their functional expression in E. coli cells and successfully characterized the photochemical properties of the purified proteins ${ }^{30}$. However, the yields of the purified proteins were $0.12 \mathrm{mg}$ for Mistic-fused ARI and $0.04 \mathrm{mg}$ for Mistic-fused $\mathrm{CrChR} 1$ per liter of culture medium, which is more than tenfold lower than those of bacterial rhodopsins ( 2 and $5 \mathrm{mg}$ for TR and Salinibacter ruber sensory rhodopsin I, respectively) $)^{9,15}$.

While organisms usually have several rhodopsin genes in their genome, the eukaryotic dinoflagellate $O$. marina uniquely shows more than 10 putative rhodopsin genes (Fig. 1B) $)^{31-33}$. O. marina is a heterotrophic dinoflagellate that is widely distributed on earth ${ }^{34}$. Noteworthy, O. marina shows several important characteristics as follows: (1) it can be isolated from the environment and easily cultured in medium, (2) genetic approaches are available, and (3) it is inexpensive to obtain, maintain and is practical to use. Therefore, O. marina has been widely used as a model for dinoflagellates for over 100 years in various scientific fields including phylogeny, biogeography and ecology ${ }^{35}$. By employing those characteristics, it has been reported that putative rhodopsin genes can be expressed as transcripts and proteins in O. marina, which suggests that those genes encode functional proteins ${ }^{31,32}$. Hartz et al. reported that $O$. marina can orient to light based on rhodopsins and may use that photosensory response to detect algal prey based on chlorophyll autofluorescence ${ }^{36}$. Based on that background, we assume that $O$. marina rhodopsins $(\mathrm{OmRs})$ would be good candidates for the functional expression and analysis of eukaryotic rhodopsins. So far, one $O m \mathrm{R}, \mathrm{OmR} 1$ (Genbank accession number: ABV22426) has been characterized by a heterologous expression system in yeast, but not by the $E$. coli cell expression system ${ }^{37}$. Thus, for expression in E. coli cells, we focused on the other gene named O. marina rhodopsin-2 (OmR2) (Genbank accession number: AIN36546). OmR2 contains several amino acids that are responsible for its outward proton pump functions such as Asp88, Thr92, Asp99 and Asp209, which correspond to Asp139, Thr143, Asp150 and Asp266 in LR, respectively (Fig. 1B and Fig. S1). Thus, OmR2 should work as an outward proton pump. It is noteworthy that $O m \mathrm{R} 2$ is phylogenetically distinct from $O m \mathrm{R} 1$ and other eukaryotic rhodopsins (Fig. 1A), where the amino acid identities and similarities of $O m \mathrm{R} 2$ with LR (15.8\% identity, $32.1 \%$ similarity) and OmR1 (17.8\% identity, 39.4\% similarity) are relatively lower than those between other characterized eukaryotic rhodopsins, suggesting its phylogenetically distinct feature.

In this study, we characterize the function and molecular properties of $O m \mathrm{R} 2$ as a new model for eukaryotic rhodopsins. We show that $O m \mathrm{R} 2$ can functionally work in E. coli cells as a recombinant protein with a lightdriven outward proton pump activity, which is confirmed to be consistent with the electrophysiological results obtained with the mammalian expression system. By taking advantage of the $E$. coli cell expression system, we obtained highly purified photoactive proteins and successfully performed spectroscopic analyses. The results indicate that $O m \mathrm{R} 2$ has similar photochemical properties to the well-characterized eukaryotic proton pump rhodopsins, which suggests that $O m \mathrm{R} 2$ can be a model for eukaryotic proton pump rhodopsins. Thus, the successful expression, purification and characterization of $O m \mathrm{R} 2$ in E. coli cells could build a basis towards understanding the molecular mechanism of eukaryotic rhodopsins.

\section{Results and discussion}

Absorption spectrum and electrophysiological experiments of OmR2 in mammalian cells. To investigate whether the $O m R 2$ gene encodes a photosensitive protein, we first expressed and purified its recombinant protein using the HEK293 cell expression system, which has been utilized for the functional expression of several eukaryotic rhodopsins from microbes and animal rhodopsins ${ }^{29,38}$. The purified OmR2 protein in detergent DDM micelles was colored purple and its absorption spectrum showed an absorption peak at $533 \mathrm{~nm}$ (Fig. 2A), indicating that $O m \mathrm{R} 2$ works as a green light sensitive protein.

We then performed an electrophysiological study to investigate the function of $O m \mathrm{R} 2$. For expression in ND7/23 cells, the cDNA for OmR2 and EYFP were inserted downstream of the CMV promoter with the trafficking signal (TS) and endoplasmic reticulum export signal (ER) to enhance the membrane localization. The corresponding gene constructs have been utilized for functional expression in mammalian cells for various kinds of microbial rhodopsins such as sodium pump rhodopsins and halorhodopsin ${ }^{39,40}$. For transfected ND7/23 cells, the yellow fluorescence from EYFP was observed especially at the plasma membrane of the cells (Fig. 2B). This indicates the successful expression and localization of $O m \mathrm{R} 2$ in the plasma membrane. We then performed electrophysiological analysis to confirm the ion transport activity of $O m R 2$. A positive photocurrent upon illumination was observed under conditions where the extracellular and intracellular $\mathrm{pH}$ were 7.4 and 7.3, respectively, and the holding membrane potential was $0 \mathrm{mV}$ (Fig. 2C). We also measured the peak currents at membrane potentials from -60 to $60 \mathrm{mV}$ to obtain the current-voltage relationship (I-V curve) (Fig. 2D). The positive peaks were kept at all potentials, which suggests that $O m R 2$ works as an outward cation pump or an inward anion pump. To further identify the substrate ion of $O m R 2$, we measured the photocurrents under 
(A)

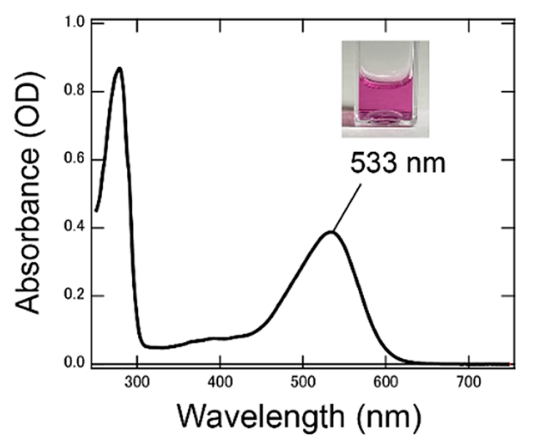

(D)

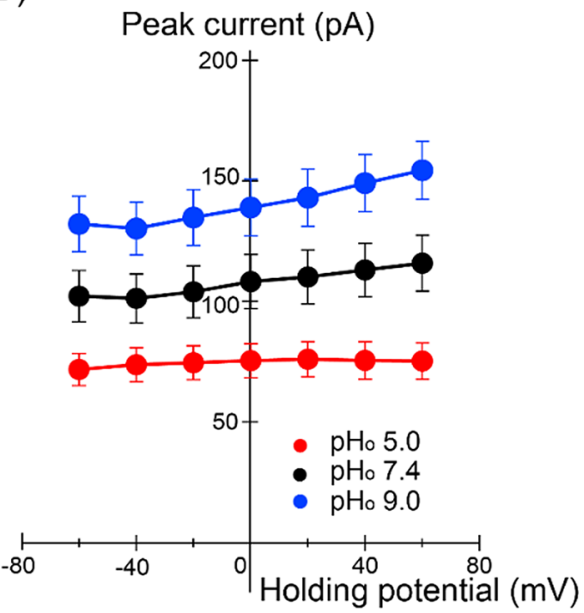

(B)

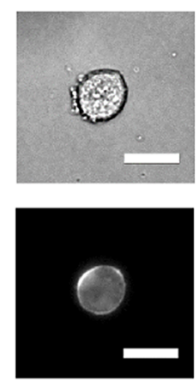

(C)

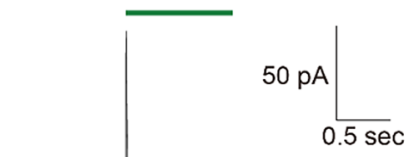

(E)

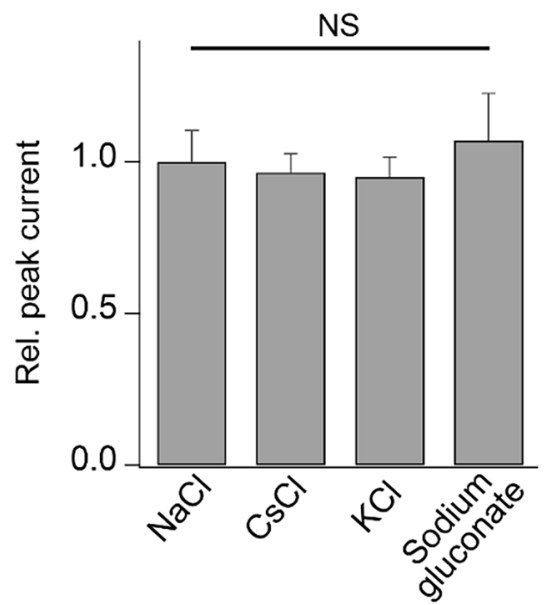

Figure 2. Absorption spectrum and electrophysiological experiments of $\mathrm{OmR} 2$ in mammalian cells. (A) Absorption spectrum of $\mathrm{OmR} 2$ purified from HEK293 cells in Buffer A containing $50 \mathrm{mM}$ Tris- $\mathrm{HCl}$ (pH 7.0), $1 \mathrm{M} \mathrm{NaCl}$ and $0.05 \%(\mathrm{w} / \mathrm{v}) \mathrm{DDM}$. The inset photograph represents the color of purified OmR2. (B) Phasecontrast image (upper panel) and fluorescence image (lower panel) of ND7/23 cells with the expression plasmid of $O m R 2$. The scale bars represent $30 \mu \mathrm{m}$. (C) Light-induced photocurrent signal at the membrane potential of $0 \mathrm{mV}$. The green bar indicates the period of illumination for $1.0 \mathrm{~s}$. (D) Current-voltage relationship ( $I-V$ curve) of $O m R 2$. The intracellular $\mathrm{pH}$ values were fixed at 7.3. Error bars indicate S.E. ( $\mathrm{n}=11-19$ cells). (E) Comparison of relative peak currents at $0 \mathrm{mV}$ with different extracellular medium conditions. There was no significant difference between the value with $\mathrm{NaCl}$ and the other values $(\mathrm{P}>0.05$; Dunnett's test).

different extracellular ion compositions. It was first observed that the higher the extracellular $\mathrm{pH}$ was set, with an intracellular $\mathrm{pH}$ of 7.3, the higher the positive peaks were at all membrane potentials (Fig. 2D). Thus, the amplitudes of peak currents were sensitive to the extracellular $\mathrm{pH}$ values. On the other hand, when $\mathrm{NaCl}$ in the extracellular solution was replaced by $\mathrm{CsCl}, \mathrm{KCl}$ or sodium gluconate, no significant change in the amplitudes was observed (Fig. 2E). These results indicate that $\mathrm{OmR} 2$ works as a light-driven outward proton pump. The peak photocurrent $(\sim 100 \mathrm{pA})$ was comparable to that of archaerhodopsin-3, AR3 $(\sim 100 \mathrm{pA})^{41}$ and a sodium pump rhodopsin KR2 $(\sim 100 \mathrm{pA})^{40}$. The successful expression and robust outward photocurrents of OmR2 suggest its applicability as a neural silencing tool for optogenetics similar to AR3 and KR2 ${ }^{22,40}$.

Functional expression of $O m R 2$ in E. coli cells. So far, the E. coli cell expression system has been widely utilized for various archaeal and bacterial rhodopsins $s^{9-13,39,41,42}$. Since $O m R 2$ is phylogenetically distinct from the other characterized eukaryotic rhodopsins, we sought to express the OmR2 recombinant protein using the $E$. coli cell expression system. We cultured E. coli BL21(DE3) cells harboring expression plasmids of OmR2. To prove that the $O m \mathrm{R} 2$ protein works as a photoactive protein, its light-dependent ion transport activity was observed as light-induced $\mathrm{pH}$ changes of a suspension of $E$. coli cells (Fig. 3). Illumination induced a $\mathrm{pH}$ decrease in the cell suspension, which would reflect the outward proton movement across the membrane while no $\mathrm{pH}$ decrease was observed in E. coli cells harboring the empty vector without the $O m \mathrm{R} 2$ gene (Fig. 3). The $\mathrm{pH}$ change disappeared in the presence of a proton-selective ionophore, CCCP, which works to collapse the proton motive force across the membrane. These results indicate that $O m \mathrm{R} 2$ has a light-dependent outward proton transport activity. In other words, OmR2 works as an outward proton pump in E. coli cells, which is consistent with the electrophysiological results for OmR2 expressed in ND7/23 cells (Fig. 2). Therefore, we concluded that the functional expression of $O m \mathrm{R} 2$ can be realized as a recombinant protein in E. coli cells. As far as we know, there has been 


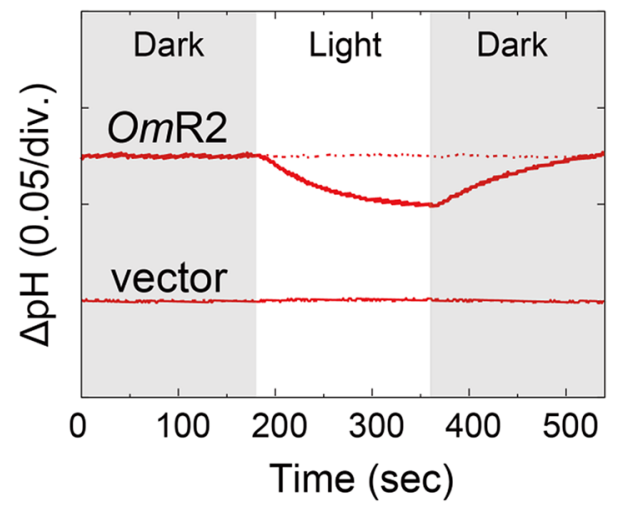

Figure 3. Outward proton pump activity of $O m \mathrm{R} 2$ in E. coli cells. Light-induced $\mathrm{pH}$ changes of solutions containing E. coli cells with the expression plasmid for OmR2 (upper panel) or the empty vector pET21a (lower panel) in the presence (red dashed lines) or absence (red solid lines) of the proton-selective ionophore, CCCP $(10 \mu \mathrm{M})$. The initial $\mathrm{pH}$ ranged from 6.4 to 6.6 . The white-filled region indicates the period of illumination.

no report that successfully obtained recombinant proteins of eukaryotic rhodopsins in E. coli cells, except for a few examples ${ }^{26,27,30}$.

To discuss what is the factor required for the successful expression of $O m \mathrm{R} 2$ in E. coli cells, we compared the amino acid sequences of $O m \mathrm{R} 2$ and other typical eukaryotic rhodopsins (Fig. 1). Among the characterized eukaryotic rhodopsins, NR is the phylogenetically closest to OmR2 but cannot be functionally expressed in E. coli cells in amounts sufficient for analysis ${ }^{43}$. It should be noted that the amino acid identity and similarity between them are 19.8 and $41.3 \%$, respectively, and therefore it is difficult to identify which element is essential for the functional expression of $O m \mathrm{R} 2$ in $E$. coli cells from the comparison between them. In addition to $O m \mathrm{R} 2$, uncharacterized and phylogenetically distinct microbial rhodopsins have been continuously identified from various eukaryotes. From comprehensive comparisons of amino acid sequences among these possible molecules that can be functionally expressed in E. coli cells, it may be possible to identify which region in eukaryotic rhodopsins is responsible for the functional expression in $E$. coli cells. To prove this concept, we will identify other molecules that can be functionally expressed in $E$. coli cells from a comprehensive expression analysis of eukaryotic rhodopsins. The region(s) conserved among them will then be introduced into molecules that could not be expressed in E. coli cells, such as NR, LR and OmR1. That approach should lead to the identification of underlying element(s) in eukaryotic rhodopsins that allow the successful functional expression in $E$. coli cells.

In addition to the sequence information, it is known that post-translational modifications (PTMs), such as glycosylation and disulfide bond formation, play important roles in the functional and structural maintenance of membrane proteins while many types of PTMs are deficient in bacteria ${ }^{44}$. We speculate that eukaryotic rhodopsins can be expressed in mammalian cells partially due to PTMs. The PTMs of OmR2 are still unclear, and therefore, further investigation is required in the future.

Purification and photochemical properties of OmR2. As described in "Methods", the E. coli cells were solubilized in DDM, after which the solubilized $\mathrm{OmR} 2$ proteins were purified by Ni-affinity column chromatography and had a purple color similar to the purified OmR2 expressed in HEK293 cells (Figs. 2A and 4A). The absorption spectrum of the purified $O m R 2$ in E. coli cells showed an absorption peak at $533 \mathrm{~nm}$ (Fig. 4A), which is consistent with the result from the purified $O m \mathrm{R} 2$ in HEK293 cells (Fig. 2A). Thus, OmR2 obtained from E. coli cells forms a photoactive pigment in the detergent micelles without significant denaturation. As far as we know, this is the first demonstration where a eukaryotic rhodopsin was purified in detergent micelles using the E. coli cell expression system, except for the previous report of Mistic-fused ARI and CrChR1 proteins ${ }^{30}$. The yield of purified $O m R 2$ protein was $1 \mathrm{mg}$ per liter of culture medium, which is more than ninefold higher than the yields of Mistic-fused ARI $(0.12 \mathrm{mg})$ and Mistic-fused CrChR1 $(0.04 \mathrm{mg})$ and is comparable to the yield of TR $(2 \mathrm{mg})^{9}$. The absorption of $O m \mathrm{R} 2$ at $\sim 280 \mathrm{~nm}$ represents the absorption of aromatic residues such as Trp and Tyr. From the ratio of absorbance at 280 and $533 \mathrm{~nm}$ with the molecular coefficient of microbial rhodopsins $\left(\sim 50,000 \mathrm{~cm}^{-1} \mathrm{M}^{-1}\right)$, we roughly estimated the purity of the sample as $67.5 \%$.

Using the purified proteins from E. coli cells, we performed the photochemical characterization of OmR2. We first performed HPLC analysis to determine the retinal configuration (Fig. 4B). The HPLC patterns of the retinal oxime isomers in the dark- and light-adapted states predominantly exhibited the peaks of all-trans isomers. The ratios of all-trans isomers were estimated to be 95 and $99 \%$, respectively, in the dark- and lightadapted states by calculating the area under the peaks considering the molecular coefficient of each isomer as previously described ${ }^{14,45}$. This indicates that $O m R 2$ possesses all-trans retinal regardless of the light environment and functions with all-trans retinal. It is generally known that archaeal proton pump rhodopsins, such as BR and AR3, possess both all-trans and 13-cis retinals whose ratio is dynamically changed according to the light environment ${ }^{46,47}$. On the other hand, bacterial and eukaryotic proton pump rhodopsins, such as PR, TR, LR and ARII, possess all-trans retinal predominantly both in dark- and in light-adapted conditions ${ }^{9}$. Similarly, OmR2 was found to possess all-trans retinal predominantly regardless of the light environment (Table 1). 

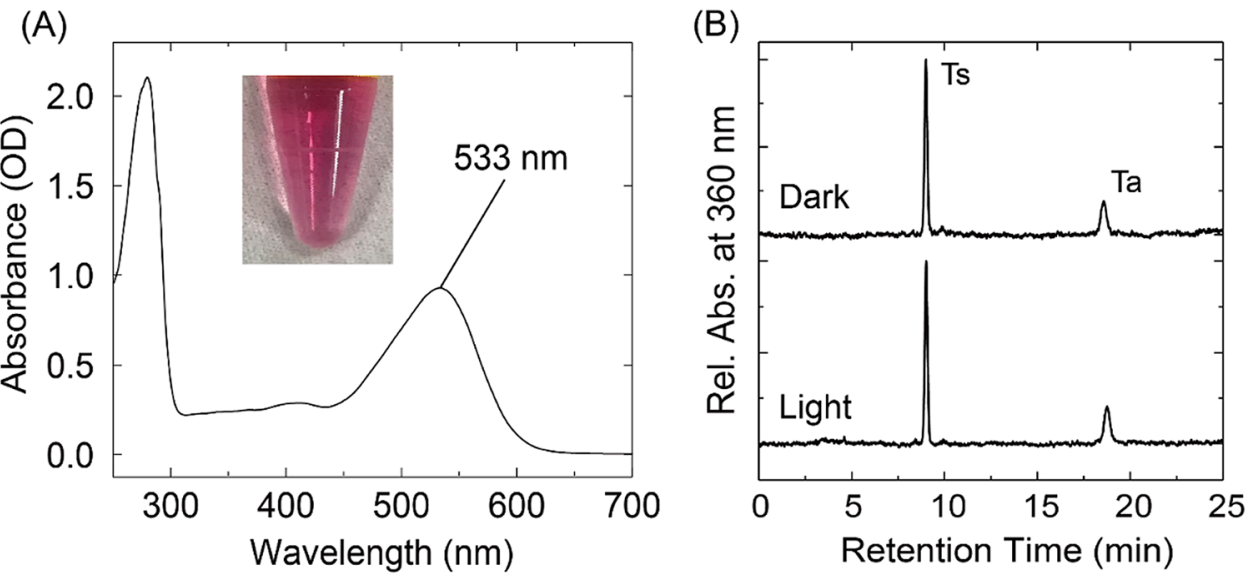

Figure 4. Absorption spectrum and retinal configuration of $O m R 2$ expressed in E. coli cells. (A) Absorption spectrum of $O m \mathrm{R} 2$ purified from E. coli cells in Buffer A containing $50 \mathrm{mM}$ Tris- $\mathrm{HCl}$ ( $\mathrm{pH} 7.0), 1 \mathrm{M} \mathrm{NaCl}$ and $0.05 \%(\mathrm{w} / \mathrm{v}) \mathrm{DDM}$. The inset photograph represents the color of purified OmR2. (B) HPLC patterns of OmR2 in dark- and light-adapted states (upper and lower traces, respectively). Ts and Ta represent all-trans-15-syn and all-trans-15-anti retinal oximes, respectively.

\begin{tabular}{|l|l|l|l|l|l|l|l|}
\hline Opsin & Origin & $\begin{array}{l}\text { Absorption } \\
\mathbf{m a x i m u m}(\mathbf{n m})\end{array}$ & $\begin{array}{l}\text { Retinal } \\
\mathbf{c o m p o s i t i o n}(\%)\end{array}$ & $\begin{array}{l}\mathbf{p} \boldsymbol{K}_{\mathbf{a}} \text { of the } \\
\text { counterion }\end{array}$ & $\begin{array}{l}\mathbf{M} \text {-decay rate } \\
\left(\mathbf{m s}^{-1}\right)\end{array}$ & $\begin{array}{l}\mathbf{O} \text {-decay rate } \\
\left(\mathbf{m s}^{-1}\right)\end{array}$ & Refs. \\
\hline OmR2 & Eukarya & 533 & All-trans (95) & $3.0($ Asp88) & 0.16 & 0.03 & This study \\
\hline OmR1 & Eukarya & 520 & All-trans (90) & 4 (Asp100) & 0.24 & 0.03 & 37 \\
\hline LR & Eukarya & 542 & All-trans (97) & N.D & 0.12 & 0.05 & 24 \\
\hline ARII & Eukarya & 534 & All-trans (96) & $2.6($ Asp81) & 0.13 & 0.13 & 48 \\
\hline BR & Archaea & 568 & $\begin{array}{l}\text { All-trans (47) } \\
\text { 13-cis (53) }\end{array}$ & $2.6($ Asp85) & 0.3 & 0.1 & 49,50 \\
\hline AR3 & Archaea & 552 & $\begin{array}{l}\text { All-trans (53) } \\
\text { 13-cis (47) }\end{array}$ & $3.1($ Asp95) & 0.45 & 0.03 & 51 \\
\hline PR & Bacteria & 525 & All-trans (95) & $7.5($ Asp97) & 4.0 & $2.8 \times 10^{-3}$ & 52 \\
\hline TR & Bacteria & 530 & All-trans (98) & $3.4($ Asp95) & $3.85 \times 10^{-3}$ & $3.95 \times 10^{-3}$ & 9 \\
\hline
\end{tabular}

Table 1. Molecular properties of $O m R 2$ and comparison with other microbial rhodopsins (N.D., not determined).

The proton pump rhodopsins are known to transfer the substrate protons through some proton acceptable charged residues such as Asp and Glu inside the proteins via the Grotthuss mechanism ${ }^{53}$. The protonated Schiff base of the retinal chromophore is stabilized by an aspartic acid as a counterion, which accepts the substrate proton from the Schiff base during the photocycle for the proton pumping function. To estimate the $\mathrm{p} K_{\mathrm{a}}$ value of the counterion of $O m R 2$, we measured its spectral changes upon acidification. When the $\mathrm{pH}$ values decreased from 7.1 to 1.7, a large spectral red-shift from 533 to $549 \mathrm{~nm}$ was observed (Fig. 5A). Interestingly, when the $\mathrm{pH}$ value further decreased to $0.98, O m \mathrm{R} 2$ showed a small spectral blue-shift from 549 to $548 \mathrm{~nm}$. The spectral red-shift can be interpreted as the protonation of the counterion leading to a decrease in the energy gap between the electronic ground and excited state, which is commonly observed in outward proton pump rhodopsins ${ }^{9,54}$. Judging from the sequence alignment between $O m R 2$ and other proton pump rhodopsins, Asp88 (Asp 85 in $\mathrm{BR}$ ) is assigned to the putative counterion in OmR2 (Fig. 1B and Fig. S1). Since a spectral blue-shift is observed at low $\mathrm{pH}$ in $\mathrm{BR}$ and is assigned to the protonation of Asp212 as a secondary counterion ${ }^{55}$, the observed small spectral blue-shift at the extremely low pH would be the protonation of Asp209 (corresponding to Asp212 in BR) as a putative secondary counterion in $O m R 2$ (Fig. 1B). The difference spectra showed the increase in absorbance at $591 \mathrm{~nm}$ and the concomitant decrease in absorbance at $516 \mathrm{~nm}$. These difference spectra did not show an isosbestic point (Fig. 5B), indicating that the process of spectral changes reflects the transition between more than three states, probably the deprotonated and protonated states of the putative counterions (Asp88 and Asp209). The plots of the difference absorbance at 591 and $516 \mathrm{~nm}$ against the acidic pH values (Fig. $5 \mathrm{C}$ ) were well fitted using the Henderson-Hasselbalch equation assuming two $\mathrm{p} K_{\mathrm{a}}$ values. From the fitting analysis, the $\mathrm{p} K_{\mathrm{a}}$ values for the spectral red-shift and blue-shift were estimated to be $3.0 \pm 0.04$ and $1.5 \pm 0.22$, respectively. Since both spectral shifts correspond to the protonation process of Asp 88 and Asp209, we estimated the $\mathrm{p} K_{\mathrm{a}}$ of the putative counterion Asp88 in $O m R 2$ as 3.0 \pm 0.04 , and the value of the secondary putative counterion Asp209 as $1.5 \pm 0.22$. The $\mathrm{p} K_{\mathrm{a}}$ of the counterion in ARII was estimated as 2.6, which is a value similar to that of OmR2 (Table 1). To determine the counterion residues of $O m R 2$ and further clarify this issue, mutational analysis of Asp88 and Asp209 will be required as future work. 

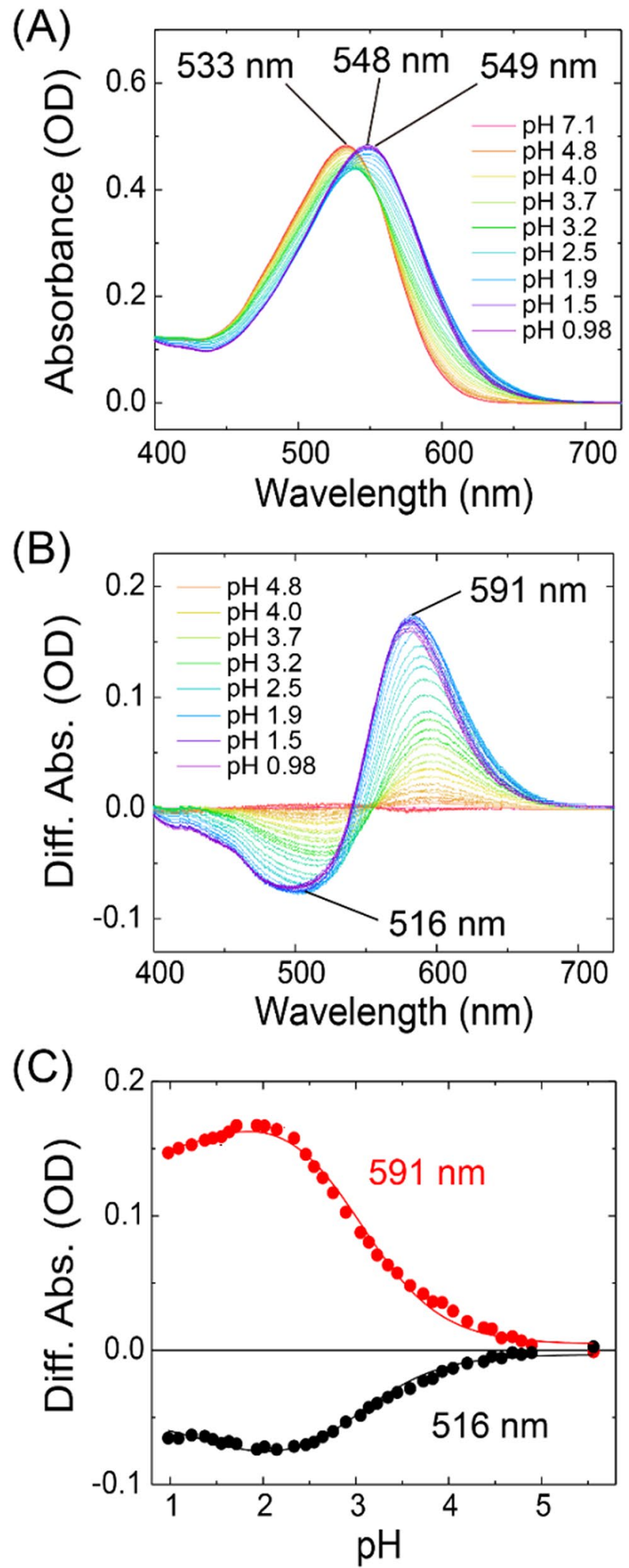

Figure 5. $\mathrm{pH}$ titration experiments of $O m \mathrm{R} 2$ at acidic conditions. (A) Absorption spectra of $O m \mathrm{R} 2$ at acidic $\mathrm{pH}$ from 7.1 to 0.98 in Buffer A containing $50 \mathrm{mM}$ Tris- $\mathrm{HCl}, 1 \mathrm{M} \mathrm{NaCl}$ and $0.05 \%$ (w/v) DDM. (B) Difference absorption spectra; each spectrum was obtained by subtracting the spectrum at $\mathrm{pH}$ 7.1. (C) Plots of the difference absorbance at 516 and $591 \mathrm{~nm}$ against the $\mathrm{pH}$ values. The titration curve was analyzed using the Henderson-Hasselbalch equation assuming double $\mathrm{p} K_{\mathrm{a}}$ values (solid lines). 
(A)

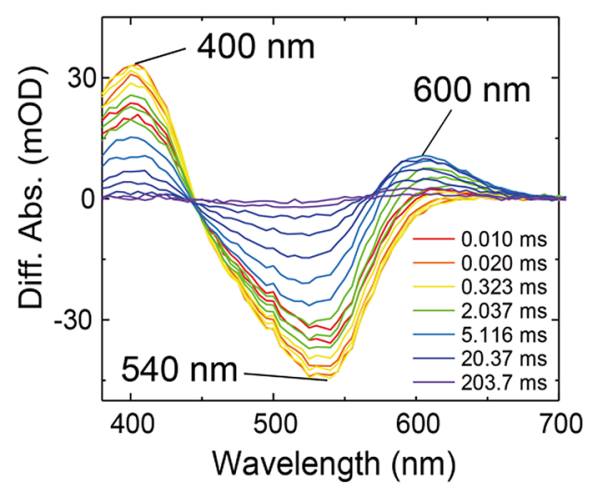

(C)

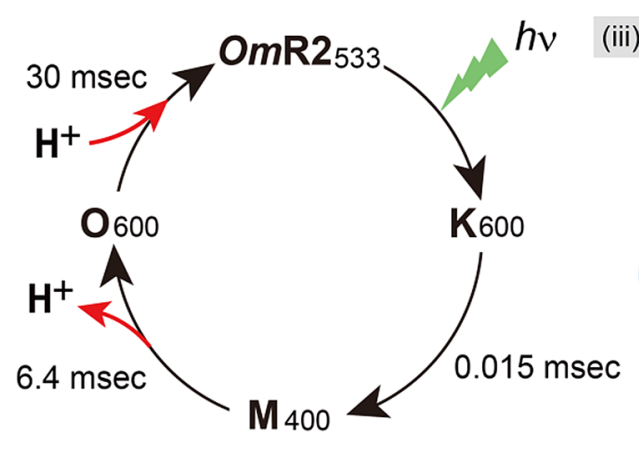

(B)

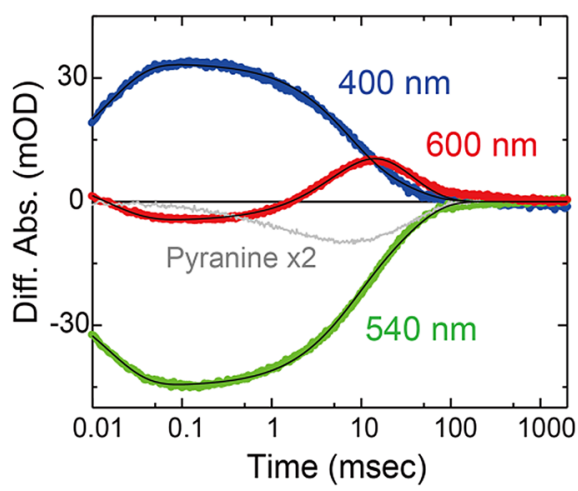

(D)

$\mathrm{H}^{+}$ Intracellular side tracellular side

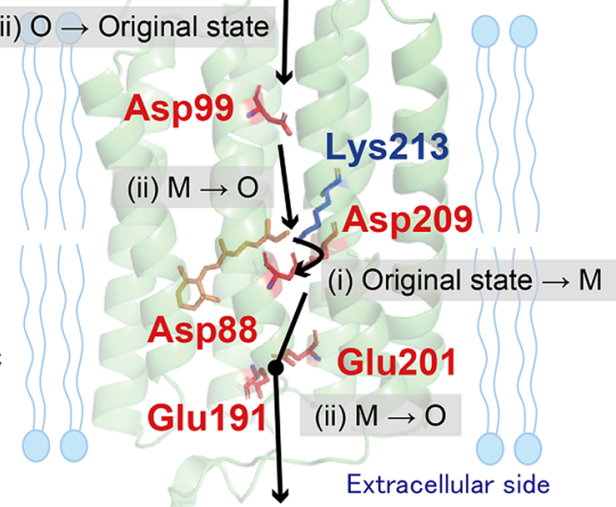

Figure 6. Photocycle and proton transport model of $O m R 2$. (A) Flash-induced difference absorption spectra over the spectral range of 380 to $710 \mathrm{~nm}$ in Buffer A containing $50 \mathrm{mM}$ Tris- $\mathrm{HCl}$ (pH 7.0), $1 \mathrm{M} \mathrm{NaCl}$ and $0.05 \%$ (w/v) DDM. (B) Time courses of absorbance changes at 400, 540 and $600 \mathrm{~nm}$. The black solid lines indicate the fitting curves. The absorption changes of pyranine monitored at $450 \mathrm{~nm}$ were enlarged 2 times and are shown as a gray solid line. (C) Proposed photocycle model of $O m R 2$ with the timing of the proton release and uptake. (D) The proton transport mechanism through some residues in $O m \mathrm{R} 2$. The pathway for putative proton transport and key residues are indicated on the homology model of $O m \mathrm{R} 2$, which was constructed from the crystal structure of ARII (PDB 3AM6) by SWISS model (https://swissmodel.expasy.org/).

Although we attempted to estimate the $\mathrm{p} K_{\mathrm{a}}$ of the protonated Schiff base of $\mathrm{OmR} 2$ by measuring its spectral changes upon alkalinization, the protein denaturation under alkaline conditions ( $>\sim \mathrm{pH} 10.5$ ) made the estimation impossible.

To analyze the photocycle of $O m \mathrm{R} 2$, we then performed flash-photolysis experiments. Figure 6A shows the flash-induced difference spectra over the spectral range of 380-710 $\mathrm{nm}$. The depletion and recovery of absorbance at $\sim 540 \mathrm{~nm}$ correspond to the bleaching of the original state, while an increase and decrease of absorbance at $\sim 400$ and $600 \mathrm{~nm}$ were characteristically observed. Figure 6B shows the time courses of the difference absorbance changes at the three wavelengths of 400, 540 and $600 \mathrm{~nm}$. Following the illumination, an absorption increase at $\sim 600 \mathrm{~nm}$ was observed together with the depletion of the original state. An absorption increase at $\sim 400 \mathrm{~nm}$ was then observed with a concomitant absorption decrease at $\sim 600 \mathrm{~nm}$ within $0.1 \mathrm{~ms}$. Considering the temporal and spectral ranges of the absorption changes, the absorbances at 600 and $400 \mathrm{~nm}$ were tentatively attributed to the $\mathrm{K}$ - and M-intermediates, respectively. The absorbance at $\sim 400 \mathrm{~nm}$ decreased with the concomitant absorbance increase at $\sim 600 \mathrm{~nm}$, which was tentatively assigned as the O-intermediate, within $50 \mathrm{~ms}$. Finally, the absorbance at $\sim 600 \mathrm{~nm}$ was depleted with recovery of the original state within $1 \mathrm{~s}$. Thus, after the light absorption, OmR2 sequentially forms K-, M- and O-intermediates, and then returns to the original state. To estimate the decay time constants of the intermediates, the temporal absorption changes at 400,540 and $600 \mathrm{~nm}$ were fitted with a triple-exponential function assuming the irreversible sequential model. The decay time constants of the K-, Mand O-intermediates were estimated as $0.015,6.4$ and $30 \mathrm{~ms}$, respectively. Finally, we investigated how proton uptake and release happen during the photocycle since $O m \mathrm{R} 2$ exhibits a proton pumping function. We measured the flash-induced absorption change at $450 \mathrm{~nm}$ of a $\mathrm{pH}$-sensitive fluorochrome, pyranine, which reflects the solvent $\mathrm{pH}$ changes as previously described ${ }^{14,42}$. As a result, the absorbance of pyranine decreased within $10 \mathrm{~ms}$ and then increased within $100 \mathrm{~ms}$. The time constants of the absorbance decrease and increase processes were estimated as 1.5 and $47 \mathrm{~ms}$, respectively, which were consistent with the formation and decay time constants 
of the O-intermediate (Fig. 6B). This suggests that the substrate proton was first released from $O m \mathrm{R} 2$ upon the $\mathrm{O}$-formation and then taken up from the bulk solution upon the $\mathrm{O}$-decay during the photocycle.

Based on the above results, we propose a photocycle model of $\mathrm{OmR} 2$ as shown schematically in Fig. 6C. It is generally known that proton pump rhodopsins carry one substrate proton per one photocycle. That means that the strength of proton pumping activities would be proportional to the period of the photocycle, which is predominantly determined by the decay time of the late intermediate such as the O-intermediate. As the decay rate of the $\mathrm{O}$-intermediate of $O m \mathrm{R} 2$ was relatively fast $\left(0.03 \mathrm{~ms}^{-1}\right)$ compared with AR3 and LR ( 0.03 and $0.05 \mathrm{~ms}^{-1}$, respectively) (Table 1), $O m \mathrm{R} 2$ can be thought to show an efficient proton pumping activity, which was demonstrated by the electrophysiological analysis (Fig. 2). As future work to clarify the photocycle model of $O m R 2$, structural investigations of each photointermediate, such as vibrational spectroscopic analysis and $\mathrm{X}$-ray crystallographic analysis, will be necessary.

Comparison of the photochemical properties of OmR2 with other proton pump rhodopsins. The photochemical properties of $O m R 2$ are listed with the well-characterized proton pump rhodopsins, OmR1, LR and ARII as eukaryotic rhodopsins, BR and AR3 as archaeal rhodopsins, and PR and TR as bacterial rhodopsins (Table 1). OmR2 possesses a deprotonated counterion (presumably Asp88 with the $\mathrm{p} K_{\mathrm{a}}$ value of 3.0) of the protonated Schiff base (Lys213) in the unphotolyzed state and shows an absorption maximum at $533 \mathrm{~nm}$ with the all-trans retinal chromophore. These properties are similar to those of OmR1, LR and ARII. During the photocycle, $O m R 2$ sequentially forms the red-shifted K-intermediate, the blue-shifted M-intermediate and the red-shifted O-intermediate, whose decay rates are similar to those of OmR1, LR and ARII. The above comparisons suggest that $O m R 2$ exhibits the typical molecular and photochemical properties present in eukaryotic proton pump rhodopsins.

$O m R 2$ contains the acidic amino acid residues that are key residues for function in outward proton pump rhodopsins (Fig. 1B and Fig. S1). Asp88 corresponds to the counterion (Asp85 in BR) that works as a proton acceptor from the Schiff base. Additionally, Asp99 corresponds to a proton donor (Asp96 in BR) and Glu191 and Glu201 correspond to the proton releasing group (Glu194 and Glu204 in BR). From the analogy with BR ${ }^{3}$, we propose the proton movement during the photocycle in $O m \mathrm{R} 2$ as follows: (i) the proton of the Schiff base is transferred to the counterion Asp88 during M-formation, (ii) the proton is released from the counterion to the extracellular side through the putative proton releasing group (Glu191 and Glu201), and simultaneously the proton of Asp99 is transferred to the Schiff base during M-decay, and (iii) the proton is taken up from the intracellular side to Asp99 during O-decay (Fig. 6D). Noteworthy, our results indicate that the proton release and uptake process correspond to the formation and decay of the $\mathrm{O}$-intermediate, suggesting the structural importance of the O-intermediate of $\mathrm{OmR} 2$. The proton uptake from the intracellular side to the proton donor residue (Asp96 in $\mathrm{BR}$ ) is generally thought to disrupt the hydrogen-bonding network between the proton donor residue and the protonated Schiff base that triggers reisomerization of retinal from the 13-cis to the all-trans form ${ }^{56}$. In fact, a proton is taken up during $\mathrm{O}$-formation in $\mathrm{BR}$ and $\mathrm{ARII}^{3,48}$. In contrast, a proton is taken up during "O-decay" in $O m \mathrm{R} 2$, suggesting its structural difference of the $\mathrm{O}$-intermediate. The structural features of the $\mathrm{O}$-intermediate should be analyzed by structural and vibrational spectroscopic measurements to further understand of the detailed proton pumping mechanism in the future. By taking advantage of the successful expression of $O m \mathrm{R} 2$ in E. coli cells, $O m \mathrm{R} 2$ will be a good model to analyze the functional mechanism of eukaryotic rhodopsins using structural and spectroscopic measurements in the future.

\section{Methods}

Construction of the phylogenetic tree of microbial rhodopsins. The protein sequences of eukaryotic rhodopsins, which were previously reported as putative proton pump rhodopsins, and rhodopsins from O. marina were obtained from the Genbank database. The protein sequences for Oxyrrhis marina rhodopsin-1 (OmR1, Genbank accession number; ABV22426), Oxyrrhis marina rhodopsin-2 (OmR2, AIN36546), Oxyrrhis marina rhodopsins (ADY17806, ADY17809, ABV22427, ABV22430, ABV22432, AIN36547, AIN36548, AIN36549) (Fig. 1B), Leptosphaeria maculans rhodopsin (LR, AAG01180) ${ }^{24}$, Phaeosphaeria nodorum rhodopsin-1 (SNOG_00807) ${ }^{57}$, Phaeosphaeria nodorum rhodopsin-2 (SNOG_00341) ${ }^{57}$, Bipolaris oryzae rhodopsin-1 (AB489199) $)^{58}$, Bipolaris oryzae rhodopsin-2 $(\mathrm{AB} 489200)^{58}$, Sclerotinia sclerotiorum rhodopsin-1 $\left(X P \_001597420\right)^{59}$, Sclerotinia sclerotiorum rhodopsin-2 (XP_001594532) $)^{59}$, Botrytis cinerea rhodopsin $\left(\mathrm{BC} 1 \mathrm{G} \_02456\right)^{60}$, Aureobasidium pullulans rhodopsin $(\mathrm{KEQ} 87154)^{61}$, Acetabularia acetabulum rhodopsin I (ARI, AEF12206) ${ }^{62}$, Acetabularia acetabulum rhodopsin II (ARII, AEF12207) ${ }^{48}$, Chlorella vulgaris rhodopsin (JQ255360) ${ }^{21}$, Coccomyxa subellipsoidea rhodopsin (CsR, XP_005646688) ${ }^{63}$, Neurospora crassa rhodopsin (NR, AAD45253) ${ }^{17}$, Fusarium fujikuroi rhodopsin (OpsA, CAR82401) $)^{64}$, Fusarium fujikuroi rhodopsin (CarO, CAD97459) ${ }^{64}$, Pseudo-nitzschia granii rhodopsin (AJA37445) ${ }^{65}$, Prorocentrum donghaiense rhodopsin $(\mathrm{KM} 282617)^{66}$, Pyrocystis lunula rhodopsin (AF508258) ${ }^{67}$, and Cyanophora paradoxa rhodopsin (ACV05065) ${ }^{68}$ were aligned using the MUSCLE algorithm in MEGA-X software (https://www.megasoftware.net/). The phylogenetic tree was inferred using the maximum likelihood method of MEGA-X software. At this time, the substitution model was selected as the LG model, a discrete Gamma distribution was used to model evolutionary rate differences among sites (five categories, $+G$ parameter $=2.32$ ), and the rate variation model allowed for sites to be evolutionarily invariable ( $1.94 \%$ sites). The bootstrap values were given by 100 iterations of the bootstrap test.

Gene preparation, protein expression and electrophysiological studies of ND7/23 cells. The full-length cDNA for $O m \mathrm{R} 2$, whose codons were optimized for human codon usage, was chemically synthesized by GenScript (Tokyo, Japan) (a kind gift from Drs Haruhiko Bito and Masayuki Sakamoto). The OmR2 gene was inserted into the CMV promoter-based mammalian expression vector (a kind gift from Drs Hiromu Yawo and 
Toru Ishizuka) as previously described ${ }^{39,40}$. In short, enhanced yellow fluorescent protein (EYFP) was fused to the C-terminus of OmR2 as a reporter. Also, EYFP was flanked with a membrane trafficking signal (TS) at the $\mathrm{N}$-terminus and an endoplasmic reticulum export signal (ER) at the C-terminus to improve its expression and plasma membrane localization. The TS and ER signals were "KSRITSEGEYIPLDQIDINV" and "FCYENEV", respectively, derived from the Kir2.1 potassium channel ${ }^{69}$. Furthermore, the WPRE (Woodchuck hepatitis virus Post-transcriptional Regulatory Element) sequence was inserted to stabilize the transcribed mRNA and increase the amount of translated protein. The expression vector encoding OmR2 was prepared with an In-Fusion cloning Kit (Takara Bio, Japan) according to the manufacturer's instructions as previously described ${ }^{28,70}$.

Electrophysiological measurements were carried out at room temperature $\left(20-25^{\circ} \mathrm{C}\right)$ with ND7/23 cells. ND7/23 cells were cultured in Dulbecco's Modified Eagle Medium (Gibco, DMEM/F12, Thermo Fisher Scientific Life Sciences, USA) supplemented with $10 \%$ fetal bovine serum, $0.0625 \%(\mathrm{w} / \mathrm{v})$ penicillin and $0.01 \%(\mathrm{w} / \mathrm{v})$ streptomycin under a $5 \% \mathrm{CO}_{2}$ atmosphere at $37^{\circ} \mathrm{C}$. The expression plasmid was transiently transfected into cells using the calcium-phosphate method ${ }^{45}$. After $6 \mathrm{~h}$ incubation of the transfected cells, all-trans retinal (final concentration $=1 \mu \mathrm{M}$ ) was added into the medium. Electrophysiological experiments were conducted 48-60 h after transfection. Transfected cells were identified by the presence of EYFP fluorescence. The fluorescence signals for EYFP were observed using an IX71 inverted microscope (Olympus, Japan) with a fluorescence mirror unit (U-MYFPHQ, Olympus) and a mercury lamp (U-LH100HGAPO, Olympus). Photocurrents were measured using an EPC 10 USB computer-controlled Patch Clamp Amplifier (HEKA Elektronik, Germany) under a whole-cell patch clamp configuration. The data were analyzed with Patch master software (HEKA Elektronik, Germany). The internal pipette solution for whole-cell voltage clamp recordings from ND7/23 cells contained $50 \mathrm{mM}$ HEPES, $140 \mathrm{mM} \mathrm{CsCl}, 3 \mathrm{mM} \mathrm{MgCl}_{2}, 5 \mathrm{mM} \mathrm{Na}_{2}$ EGTA and $2.5 \mathrm{mM} \mathrm{MgATP}$, adjusted to $\mathrm{pH} 7.3$ with CsOH. The cells were continuously superfused by an extracellular medium (10 mM HEPES, $138 \mathrm{mM} \mathrm{NaCl}, 3 \mathrm{mM} \mathrm{KCl}, 1 \mathrm{mM} \mathrm{MgCl}$, $2 \mathrm{mM} \mathrm{CaCl}_{2}, 0.1 \mathrm{M}$ glucose, adjusted to $\mathrm{pH} 9.0,7.4$ and 5.0 with $\mathrm{NaOH}$ or $\mathrm{HCl}$ ). To investigate pump activity in the absence of extracellular chloride, sodium and the presence of potassium, $\mathrm{NaCl}$ was also substituted by the same amount of sodium gluconate, $\mathrm{CsCl}, \mathrm{KCl}$. Current traces were recorded at $-60,-40,-20,0,20,40$ and $60 \mathrm{mV}$. The cells were illuminated with a white LED (THORLABS, USA) through a band-pass filter $(520 \pm 10 \mathrm{~nm})$, where the light intensity was adjusted to $0.98 \mathrm{~mW} \mathrm{~mm}^{-2}$.

Gene preparation, protein expression and purification of HEK293T cells. For protein expression and purification, the human codon-optimized $O m R 2$ gene was inserted into a CAG promoter-based mammalian expression vector, pCAGGS, as previously described ${ }^{29}$. A hexa-histidine tag was fused to the C-terminus of $O m \mathrm{R} 2$. The expression vector encoding $O m \mathrm{R} 2$ was prepared using an In-Fusion cloning Kit. For protein expression in HEK293T cells, the plasmid was transfected into the cells using the calcium-phosphate method ${ }^{29,38}$. After 1 day incubation, all-trans-retinal (final concentration $=5 \mu \mathrm{M}$ ) was added to the transfected cells ${ }^{29,38}$. After another day of incubation, the cells were collected by centrifugation and were then solubilized with $1.0 \%$ $(\mathrm{w} / \mathrm{v}) \mathrm{n}$-dodecyl- $\beta$-D-maltoside (DDM, DOJINDO Laboratories, Japan). The solubilized fraction was purified by $\mathrm{Ni}^{2+}$ affinity column chromatography with a linear gradient of imidazole as described previously ${ }^{29}$. The purified protein was concentrated by centrifugation using an Amicon Ultra filter (30,000 $\mathrm{M}_{\mathrm{w}}$ cut-off; Millipore, USA). The sample was then loaded into and eluted from a PD-10 column (GE-Healthcare, UK) with Buffer A (50 mM Tris-HCl, pH 7.0, $1 \mathrm{M} \mathrm{NaCl}$ and $0.05 \%$ (w/v) DDM).

Gene preparation, protein expression and ion transport measurements of $E$. coli cells. The full-length cDNA for $O m$ R2, whose codons were optimized for E. coli codon usage, were chemically synthesized by Eurofins Genomics and inserted into the NdeI-XhoI site of the pET21a(+) vector as previously described ${ }^{14}$. A hexa-histidine-tag was fused at the C-terminus of $O m \mathrm{R} 2$, which was utilized for purification of the expressed protein. The procedures for protein expression were essentially the same as previously described ${ }^{14,42}$. E. coli BL21(DE3) cells harboring the cognate plasmid were grown at $37^{\circ} \mathrm{C}$ in LB medium supplemented with ampicillin (final concentration $\left.=50 \mu \mathrm{g} \mathrm{mL}^{-1}\right)$. Protein expression was induced at an optical density at $600 \mathrm{~nm}\left(\mathrm{OD}_{600}\right)$ of $0.8-1.2$ with $1 \mathrm{mM}$ isopropyl $\beta$-D-1-thiogalactopyranoside (IPTG) and $10 \mu \mathrm{M}$ all-trans retinal, after which the cells were incubated at $37^{\circ} \mathrm{C}$ for $3 \mathrm{~h}$. The proton transport activity of $\mathrm{OmR} 2$ was measured as light-induced $\mathrm{pH}$ changes of suspensions of $E$. coli cells as previously described ${ }^{14,42}$. In short, cells expressing OmR2 were washed more than three times in $150 \mathrm{mM} \mathrm{NaCl}$ and were then resuspended in the same solution for measurements. Each cell suspension was placed in the dark for several min and then illuminated using a $300 \mathrm{~W}$ Xenon lamp (ca. $30 \mathrm{~mW} \mathrm{~cm}{ }^{-2}$, MAX-303, Asahi spectra, Japan) through a $>460 \mathrm{~nm}$ long-pass filter (Y48, HOYA, Japan) for $3 \mathrm{~min}$. Measurements were repeated under the same conditions after addition of the protonophore carbonyl cyanide $\mathrm{m}$-chlorophenylhydrazone $(\mathrm{CCCP})$ (final concentration $=10 \mu \mathrm{M}$ ). Light-induced $\mathrm{pH}$ changes were monitored using a Horiba F-72 pH meter. All measurements were conducted at $25^{\circ} \mathrm{C}$ using a thermostat (Eyela NCB-1200, Tokyo Rikakikai Co. Ltd, Japan).

Purification of OmR2 from E. coli cells and spectroscopic measurements of the purified protein. Escherichia coli cells expressing $O m \mathrm{R} 2$ were disrupted by sonication for $30 \mathrm{~min}$ in ice-cold water in Buffer B containing $50 \mathrm{mM}$ Tris- $\mathrm{HCl}$ (pH 7.0) and $300 \mathrm{mM} \mathrm{NaCl}$. The crude membrane fraction was collected by ultracentrifugation and solubilized with $1.0 \%(\mathrm{w} / \mathrm{v}) \mathrm{DDM}$. The solubilized fraction was purified by $\mathrm{Ni}^{2+} \mathrm{affin}^{-}$ ity column chromatography with a linear gradient of imidazole as described previously ${ }^{14,42}$. The purified protein was concentrated by centrifugation using an Amicon Ultra filter (30,000 $\mathrm{M}_{\mathrm{w}}$ cut-off; Millipore, USA). The sample media was then replaced with Buffer A by ultrafiltration for 3-times.

Absorption spectra of purified proteins were recorded using a UV-2450 spectrophotometer (Shimadzu, Japan) at room temperature in Buffer A. The retinal composition in $\mathrm{O} m \mathrm{R} 2$ was analyzed by high-performance liquid 
chromatography (HPLC) as described previously ${ }^{14}$. For light-adaptation, the samples were illuminated for 3 min at $530 \pm 10 \mathrm{~nm}$, where the light power was adjusted to $\sim 10 \mathrm{~mW} \mathrm{~cm}^{-2}$. The molar compositions of the retinal isomers were calculated from the areas of the peaks in HPLC patterns monitored at $360 \mathrm{~nm}$ using the extinction coefficients of retinal oxime isomers as described previously ${ }^{14,45}$. For $\mathrm{pH}$ titration experiments, the samples were suspended in Buffer A. The $\mathrm{pH}$ values of the samples were adjusted to the desired acidic values by adding $\mathrm{HCl}$, after which the absorption spectra were measured at each $\mathrm{pH}$ value. All measurements were conducted at room temperature (approx. $25^{\circ} \mathrm{C}$ ) under room light. After the measurements, the reversibility of the spectral changes was checked to confirm that the sample was not denatured during the measurements. The absorption changes at specific wavelengths were plotted against $\mathrm{pH}$ values and the plots were fitted to the Henderson-Hasselbalch equation assuming double $\mathrm{p} K_{\mathrm{a}}$ values as previously described ${ }^{14}$.

Transient time-resolved absorption spectra of the purified proteins from 380 to $700 \mathrm{~nm}$ at $5 \mathrm{~nm}$ intervals were obtained using a homemade computer-controlled flash photolysis system equipped with an Nd:YAG laser as an actinic light source ${ }^{14,42}$. By using an optical parametric oscillator, the wavelength of the actinic pulse was tuned at $530 \mathrm{~nm}$ for $O m R 2$. The pulse intensity was adjusted to $2 \mathrm{~mJ}$ per pulse. All data were averaged to improve the signal-to-noise ratio $(n=30)$. All measurements were conducted at $25^{\circ} \mathrm{C}$. For these experiments, the samples were suspended in Buffer A. After the measurements, the reproducibility of the data was checked to confirm that the sample was not denatured during the measurements. To investigate proton uptake and release during the photocycle, we used the $\mathrm{pH}$ indicator pyranine (final concentration $=100 \mu \mathrm{M}$, Tokyo Chemical Industry Co., Ltd, Japan), which has been extensively used to monitor light-induced $\mathrm{pH}$ changes in various rhodopsins ${ }^{14,42}$. The $\mathrm{pH}$ changes in the bulk environment were measured as the absorption changes of pyranine at $450 \mathrm{~nm}$. The absorption changes of pyranine were obtained by subtracting the absorption changes of samples without pyranine from those of samples with pyranine. The experiments using pyranine were performed in an unbuffered solution containing $1 \mathrm{M} \mathrm{NaCl}$ and $0.05 \%(\mathrm{w} / \mathrm{v}) \mathrm{DDM}(\mathrm{pH} 7.0)$ to enhance the signals. The results of 1000 -traces were averaged to improve the signal-to-noise ratio.

Received: 12 May 2021; Accepted: 7 July 2021

Published online: 20 July 2021

\section{References}

1. Govorunova, E. G., Sineshchekov, O. A., Li, H. \& Spudich, J. L. Microbial rhodopsins: Diversity, mechanisms, and optogenetic applications. Annu. Rev. Biochem. 86, 845-872 (2017).

2. Kojima, K., Shibukawa, A. \& Sudo, Y. The unlimited potential of microbial rhodopsins as optical tools. Biochemistry 59, 218-229 (2020).

3. Ernst, O. P. et al. Microbial and animal rhodopsins: Structures, functions, and molecular mechanisms. Chem. Rev. 114, 126-163 (2014).

4. Pinhassi, J., DeLong, E. F., Béjà, O., Gonzalez, J. M. \& Pedros-Alio, C. Marine bacterial and archaeal ion-pumping rhodopsins: Genetic diversity, physiology, and ecology. Microbiol. Mol. Biol. Rev. 80, 929-954 (2016).

5. Oesterhelt, D. \& Stoeckenius, W. Rhodopsin-like protein from the purple membrane of Halobacterium halobium. Nat. New. Biol. 233, 149-152 (1971).

6. Lanyi, J. K. Bacteriorhodopsin. Annu. Rev. Physiol. 66, 665-688 (2004).

7. Béjà, O. et al. Bacterial rhodopsin: Evidence for a new type of phototrophy in the sea. Science 289, 1902-1906 (2000).

8. Béjà, O., Spudich, E. N., Spudich, J. L., Leclerc, M. \& DeLong, E. F. Proteorhodopsin phototrophy in the ocean. Nature 411, 786-789 (2001).

9. Tsukamoto, T., Inoue, K., Kandori, H. \& Sudo, Y. Thermal and spectroscopic characterization of a proton pumping rhodopsin from an extreme thermophile. J. Biol. Chem. 288, 21581-21592 (2013).

10. Tsukamoto, T. et al. X-ray crystallographic structure of thermophilic rhodopsin: Implications for high tehrmal stability and optogenetic function. J. Biol. Chem. 291, 12223-12232 (2016).

11. Inoue, K. et al. A light-driven sodium ion pump in marine bacteria. Nat. Commun. 4, 1678 (2013).

12. Jung, K. H., Trivedi, V. D. \& Spudich, J. L. Demonstration of a sensory rhodopsin in eubacteria. Mol. Microbiol. 47, 1513-1522 (2003).

13. Shimono, K., Iwamoto, M., Sumi, M. \& Kamo, N. Functional expression of pharaonis phoborhodopsin in Escherichia coli. FEBS Lett. 420, 54-56 (1997).

14. Inoue, S. et al. Spectroscopic characteristics of Rubricoccus marinus xenorhodopsin (RmXeR) and a putative model for its inward $\mathrm{H}^{+}$transport mechanism. Phys. Chem. Chem. Phys. 20, 3172-3183 (2018).

15. Kitajima-Ihara, T. et al. Salinibacter sensory rhodopsin: Sensory rhodopsin I-like protein from a eubacterium. J. Biol. Chem. 283, 23533-23541 (2008).

16. Irieda, H. et al. Photo-induced regulation of the chromatic adaptive gene expression by Anabaena sensory rhodopsin. J. Biol. Chem. 287, 32485-32493 (2012).

17. Bieszke, J. A. et al. The nop-1 gene of Neurospora crassa encodes a seven transmembrane helix retinal-binding protein homologous to archaeal rhodopsins. Proc. Natl. Acad. Sci. USA 96, 8034-8039 (1999).

18. Nagel, G. et al. Channelrhodopsin-1: A light-gated proton channel in green algae. Science 296, 2395-2398 (2002).

19. Nagel, G. et al. Channelrhodopsin-2, a directly light-gated cation-selective membrane channel. Proc. Natl. Acad. Sci. USA 100, 13940-13945 (2003).

20. Govorunova, E. G., Sineshchekov, O. A., Janz, R., Liu, X. \& Spudich, J. L. NEUROSCIENCE. Natural light-gated anion channels: A family of microbial rhodopsins for advanced optogenetics. Science 349, 647-650 (2015).

21. Zhang, F. et al. The microbial opsin family of optogenetic tools. Cell 147, 1446-1457 (2011).

22. Chow, B. et al. High-performance genetically targetable optical neural silencing by light-driven proton pumps. Nature 463, 98-102 (2010).

23. Tsunoda, S. P. et al. $\mathrm{H}^{+}$-pumping rhodopsin from the marine alga Acetabularia. Biophys. J. 91, 1471-1479 (2006).

24. Waschuk, S. A., Bezerra, A. G. Jr., Shi, L. \& Brown, L. S. Leptosphaeria rhodopsin: Bacteriorhodopsin-like proton pump from a eukaryote. Proc. Natl. Acad. Sci. USA 102, 6879-6883 (2005).

25. Wada, T. et al. Crystal structure of the eukaryotic light-driven proton-pumping rhodopsin, Acetabularia rhodopsin II, from marine alga. J. Mol. Biol. 411, 986-998 (2011). 
26. Doi, S. et al. Structural and functional roles of the N- and C-terminal extended modules in channelrhodopsin-1. Photochem. Photobiol. Sci. 14, 1628-1636 (2015).

27. Doi, S., Tsukamoto, T., Yoshizawa, S. \& Sudo, Y. An inhibitory role of Arg-84 in anion channelrhodopsin-2 expressed in Escherichia coli. Sci. Rep. 7, 41879 (2017).

28. Kojima, K. et al. Mutational analysis of the conserved carboxylates of anion channelrhodopsin-2 (ACR2) expressed in Escherichia coli and their roles in anion transport. Biophys. Physicobiol. 15, 179-188 (2018).

29. Kojima, K. et al. Green-sensitive, long-lived, step-functional anion channelrhodopsin-2 variant as a high-potential neural silencing tool. J. Phys. Chem. Lett. 11, 6214-6218 (2020).

30. Lee, K. A. et al. Mistic-fused expression of algal rhodopsins in Escherichia coli and its photochemical properties. Biochim. Biophys. Acta 1850, 1694-1703 (2015).

31. Slamovits, C. H., Okamoto, N., Burri, L., James, E. R. \& Keeling, P. J. A bacterial proteorhodopsin proton pump in marine eukaryotes. Nat. Commun. 2, 183 (2011).

32. Guo, Z., Zhang, H. \& Lin, S. Light-promoted rhodopsin expression and starvation survival in the marine dinoflagellate Oxyrrhis marina. PLoS ONE 9, e114941 (2014).

33. Zhang, H. et al. Spliced leader RNA trans-splicing in dinoflagellates. Proc. Natl. Acad. Sci. USA 104, 4618-4623 (2007).

34. Watts, P. C., Martin, L. E., Kimmance, S. A., Montagnes, D. J. S. \& Lowe, C. D. The distribution of Oxyrrhis marina: A global disperser or poorly characterized endemic?. J. Plankton Res. 33, 579-589 (2011).

35. Montagnes, D. J. S. et al. Oxyrrhis marina growth, sex and reproduction. J. Plankton Res. 33, 615-627 (2011).

36. Hartz, A. J., Sherr, B. F. \& Sherr, E. B. Photoresponse in the heterotrophic marine dinoflagellate Oxyrrhis marina. J. Eukaryot. Microbiol. 58, 171-177 (2011).

37. Janke, C. et al. Photocycle and vectorial proton transfer in a rhodopsin from the eukaryote Oxyrrhis marina. Biochemistry 52, 2750-2763 (2013).

38. Yamashita, T. et al. Opn5 is a UV-sensitive bistable pigment that couples with Gi subtype of G protein. Proc. Natl. Acad. Sci. USA 107, 22084-22089 (2010).

39. Hoque, M. R. et al. A chimera $\mathrm{Na}^{+}$-pump rhodopsin as an effective optogenetic silencer. PLoS ONE 11, e0166820 (2016).

40. Kato, H. E. et al. Structural basis for $\mathrm{Na}^{+}$transport mechanism by a light-driven $\mathrm{Na}^{+}$pump. Nature 521, 48-53 (2015).

41. Takayama, R. et al. Production of a light-gated proton channel by replacing the retinal chromophore with its synthetic vinylene derivative. J. Phys. Chem. Lett. 9, 2857-2862 (2018).

42. Kojima, K. et al. Vectorial proton transport mechanism of RxR, a phylogenetically distinct and thermally stable microbial rhodopsin. Sci. Rep. 10, $282(2020)$.

43. Brown, L. S., Dioumaev, A. K., Lanyi, J. K., Spudich, E. N. \& Spudich, J. L. Photochemical reaction cycle and proton transfers in Neurospora rhodopsin. J. Biol. Chem. 276, 32495-32505 (2001).

44. Mann, M. \& Jensen, O. N. Proteomic analysis of post-translational modifications. Nat. Biotechnol. 21, 255-261 (2003).

45. Kojima, K. et al. Evolutionary steps involving counterion displacement in a tunicate opsin. Proc. Natl. Acad. Sci. USA 114, 60286033 (2017).

46. Pettei, M. J., Yudd, A. P., Nakanishi, K., Henselman, R. \& Stoeckenius, W. Identification of retinal isomers isolated from bacteriorhodopsin. Biochemistry 16, 1955-1959 (1977).

47. Sudo, Y. et al. A blue-shifted light-driven proton pump for neural silencing. J. Biol. Chem. 288, 20624-20632 (2013).

48. Kikukawa, T. et al. Photochemistry of Acetabularia rhodopsin II from a marine plant, Acetabularia acetabulum. Biochemistry 50, 8888-8898 (2011).

49. Oesterhelt, D., Meentzen, M. \& Schuhmann, L. Reversible dissociation of the purple complex in bacteriorhodopsin and identification of 13-cis and all-trans-retinal as its chromophores. Eur. J. Biochem. 40, 453-463 (1973).

50. Balashov, S. P. Protonation reactions and their coupling in bacteriorhodopsin. Biochim. Biophys. Acta. 1460, 75-94 (2000).

51. Inoue, K. et al. Converting a light-driven proton pump into a light-gated proton channel. J. Am. Chem. Soc. 137, 3291-3299 (2015).

52. Bamann, C., Bamberg, E., Wachtveitl, J. \& Glaubitz, C. Proteorhodopsin. Biochim. Biophys. Acta. 1837, 614-625 (2014).

53. Marx, D. Proton transfer 200 years after von Grotthuss: Insights from ab initio simulations. Chem. Phys. Chem. 7, 1848-1870 (2006).

54. Brown, L. S., Bonet, L., Needleman, R. \& Lanyi, J. K. Estimated acid dissociation constants of the Schiff base, Asp-85, and Arg-82 during the bacteriorhodopsin photocycle. Biophys. J. 65, 124-130 (1993).

55. Needleman, R. et al. Properties of Asp212 $\rightarrow$ Asn bacteriorhodopsin suggest that Asp212 and Asp85 both participate in a counterion and proton acceptor complex near the Schiff base. J. Biol. Chem. 266, 11478-11484 (1991).

56. Dioumaev, A. K., Brown, L. S., Needleman, R. \& Lanyi, J. K. Coupling of the reisomerization of the retinal, proton uptake, and reprotonation of Asp-96 in the N photointermediate of bacteriorhodopsin. Biochemistry 40, 11308-11317 (2001).

57. Fan, Y., Solomon, P., Oliver, R. P. \& Brown, L. S. Photochemical characterization of a novel fungal rhodopsin from Phaeosphaeria nodorum. Biochim. Biophys. Acta. 1807, 1457-1466 (2011).

58. Kihara, J., Tanaka, N., Ueno, M. \& Arase, S. Cloning and expression analysis of two opsin-like genes in the phytopathogenic fungus Bipolaris oryzae. FEMS Microbiol. Lett. 295, 289-294 (2009).

59. Lyu, X. et al. The microbial opsin homolog Sop1 is involved in Sclerotinia sclerotiorum development and environmental stress response. Front. Microbiol. 6, 1504 (2015).

60. Heller, J. et al. The mitogen-activated protein kinase BcSak1 of Botrytis cinerea is required for pathogenic development and has broad regulatory functions beyond stress response. Mol. Plant. Microbe. Interact. 25, 802-816 (2012).

61. Gostincar, C. et al. Genome sequencing of four Aureobasidium pullulans varieties: Biotechnological potential, stress tolerance, and description of new species. BMC Genom. 15, 549 (2014).

62. Lee, S. S. et al. Acetabularia rhodopsin I is a light-stimulated proton pump. J. Nanosci. Nanotechnol. 11, 4596-4600 (2011).

63. Ranjan, P. \& Kateriya, S. Localization and dimer stability of a newly identified microbial rhodopsin from a polar, non-motile green algae. BMC Res. Notes. 11, 65 (2018).

64. Garcia-Martinez, J., Brunk, M., Avalos, J. \& Terpitz, U. The CarO rhodopsin of the fungus Fusarium fujikuroi is a light-driven proton pump that retards spore germination. Sci. Rep. 5, 7798 (2015).

65. Marchetti, A., Catlett, D., Hopkinson, B. M., Ellis, K. \& Cassar, N. Marine diatom proteorhodopsins and their potential role in coping with low iron availability. ISME J. 9, 2745-2748 (2015).

66. Shi, X. et al. Rhodopsin gene expression regulated by the light dark cycle, light spectrum and light intensity in the dinoflagellate Prorocentrum. Front. Microbiol. 6, 555 (2015).

67. Okamoto, O. K. \& Hastings, J. W. Novel dinoflagellate clock-related genes identified through microarray analysis. J. Phycol. 39, $519-526(2003)$.

68. Frassanito, A. M., Barsanti, L., Passarelli, V., Evangelista, V. \& Gualtieri, P. A rhodopsin-like protein in Cyanophora paradoxa: gene sequence and protein immunolocalization. Cell. Mol. Life Sci. 67, 965-971 (2010).

69. Gradinaru, V. et al. Molecular and cellular approaches for diversifying and extending optogenetics. Cell 141, 154-165 (2010).

70. Kojima, K. et al. Adaptation of cone pigments found in green rods for scotopic vision through a single amino acid mutation. Proc. Natl. Acad. Sci. USA 114, 5437-5442 (2017). 


\section{Acknowledgements}

We wish to thank Drs. Masayuki Sakamoto and Haruhiko Bito for providing the expression plasmid of $O m \mathrm{R} 2$ for mammalian cells. This work was financially supported by JSPS KAKENHI Grant Numbers JP19K16090 to KK, JP18H04136 to SY, JP17K07326 to TK, JP19H04727, JP19H05396, JP20K21482, JP21H0040413, JP18H02411, and JP21H0244613 to YS. This research was partially supported by JST CREST (JPMJCR1656) and AMED (20dm0207060h0004) to YS. The authors also thank "DASS Manuscript" (http://www.dass-ms.com/home.html) for the English language review.

\section{Author contributions}

K.K. and Y.S. designed the experiments. M.K., K.K., S.N. and S.K. performed the experiments. M.K., K.K., S.N., S.Y., A.S., T.K. and Y.S. analyzed the data. K.K. and Y.S. wrote the paper. All authors reviewed the manuscript.

\section{Competing interests}

The authors declare no competing interests.

\section{Additional information}

Supplementary Information The online version contains supplementary material available at https://doi.org/ 10.1038/s41598-021-94181-w.

Correspondence and requests for materials should be addressed to Y.S.

Reprints and permissions information is available at www.nature.com/reprints.

Publisher's note Springer Nature remains neutral with regard to jurisdictional claims in published maps and institutional affiliations.

(c) (i) Open Access This article is licensed under a Creative Commons Attribution 4.0 International License, which permits use, sharing, adaptation, distribution and reproduction in any medium or format, as long as you give appropriate credit to the original author(s) and the source, provide a link to the Creative Commons licence, and indicate if changes were made. The images or other third party material in this article are included in the article's Creative Commons licence, unless indicated otherwise in a credit line to the material. If material is not included in the article's Creative Commons licence and your intended use is not permitted by statutory regulation or exceeds the permitted use, you will need to obtain permission directly from the copyright holder. To view a copy of this licence, visit http://creativecommons.org/licenses/by/4.0/.

(C) The Author(s) 2021 